INTERNATIONAL JOURNAL OF RESEARCHES IN BIOSCIENCES, AGRICULTURE AND TECHNOLOGY (C) VISHWASHANTI MULTIPURPOSE SOCIETY (Global Peace Multipurpose Society) R. No. MH-659/13(N) www.vmsindia.org

\title{
EFFECT OF SOLUBLE CHITOSAN APPLICATION ON IN VITRO GERMINATION AND GROWTH OF DORMANT CORMS OF COLCHICUM LUTEUM BAKER
}

\author{
P. J., Wagh ${ }^{1}$, V. W., Patil ${ }^{2}$ and M. C. Kale ${ }^{1}$ \\ ${ }^{1}$ Botany Department, Anand Niketan College, Anandwan, Warora, Dist- Chandrapur - 442914 \\ ${ }^{2}$ Botany Department, I. C. S. College of Arts, Commerce and Science, Khed, Dist - Ratnagiri - 405709 \\ *pwagh79@gmail.com
}

\begin{abstract}
:
Corms and the above ground parts of the yellow meadow saffron (Colchicum luteum Baker) have been proposed for the isolation of colchicine and colchamine in our country. Corms are collected and stored in large quantities for the extraction which result in rapid depletion of the raw material sources. In order to investigate the effects of chitosan on germination and growth of corms of Colchicum luteum Baker, corms were treated in vitro with soluble chitosan at different concentrations including $0,0.005,0.015,0.05,0.15,0.5,0.75$ and 1 gm/1 added to the MS tissue culture medium. Germinated corms were evaluated for growth parameters in vitro only. At the concentrations of 0.75 and $1 \mathrm{~g} / 1$ of chitosan the culture medium failed to solidify. Application of $0.5 \mathrm{~g} / 1$ of chitosan increased the germination percentage, shoot fresh weight as compared to untreated, but its lower concentration did not significantly affect this trait $(\mathrm{P}<0.05)$. The 0.015 and $0.5 \mathrm{~g} / 1$ of chitosan led to a significant increase in shoot length and dry weight of in vitro plantlets. The present results indicate that soluble chitosan can be successfully incorporated into culture medium for in vitro germination of Colchicum corms stored at room temperature over period of one year.

Keywords: chitosan; Colchicum; corms; in vitro germination; growth; MS medium.
\end{abstract}

\section{Introduction:}

Colchicum luteum Baker belonging to the family Colchicaceae is a valuable medicinal plant [Fig. 1 a)]. It is a small herb with globose corm, covered with brown scales and found above 2000 meters altitude [Fig. 1 b)]. In rural India corms are used for various ailments (Chopra, 1969). This species yields an alkaloid called colchicine (Kapadia et al., 1972). The use of colchicine is well established and mainly used as drug against rheumatism, as a laxative, and in diseases of skin and liver (Eigsti and Dustin, 1957). Moreover, colchicine is well known for its use in plant and animal genetics because of its property in inducing metaphase arrest. The species of Colchicum grow only in high altitude of Western Himalayas. Their restricted distribution at a very high altitude and their limited period of growth are the reasons for the low yield of this plant which cannot meet the demand for world market. The corm and seeds of $C$. autumnale and C. luteum contain 0.2-0.5 $\mathrm{g} / 100 \mathrm{~g}$ dry weight of colchicine (Wealth of India, 1959; Kapadia et al., 1972). Because of its colchicine content, its potential as a source of alkaloid has been indicated (Wealth of India, 1959). Despite their importance, no systematic attempt has been made for mass propagation of elite genotypes of this species with a high content of active principle. The restricted distribution and indiscriminate over-exploitation of this plant for medicinal use have endangered its survival. Tissue culture approaches are needed for this reason to get rapid propagation as in vitro protocol for micro propagation can be utilized for commercial exploitation as well.

Chitosan is a large cationic polysaccharide mainly obtained from waste materials from seafood processing. Chitosan has gained special attention as biotic elicitor for the production of phytoalexins and secondary metabolites in plants and cell cultures (Yamaguchi et al., 2000, Day et al., 2001). Chitosan, is found to improve vegetative growth of grapevine plantlets during in vitro culture (Ait Barka et al., 2004). It has also been shown that chitosan promotes vegetative growth and enhances various processes in developing flower buds of Eustoma grandiflorum (Ohta et al., 1999 and Uddin et al., 2004). Chitosan treatment for improving seed germination, growth and induced resistance has been reported by several workers in different crops like wheat (Reddy et al., 1999; Saoji, 2008), peanut (Zhou et al., 2002), rice (Ruan and Xue, 2002), carrot (Cheah et al., 1997), maize (Shao et al., 2005), chilli, Chinese cabbage, celery, bitter cucumber and rice (Chandrkrachang et al. 2003; Boonlertnirun et al., 2008), tomato, spinach and coriander (Wagh, 2012). Thus, it seems that chitosan is a promising material for germination treatments.

Present work is an attempt for improving germination efficiency of dormant Colchicum luteum Baker corms using soluble chitosan. 


\section{Material and Method:}

Underground, dried and dormant corms of Colchicum luteum Baker were collected from, Kumbathang (Latitude: 34²3'38.65"; Longitude: $\left.75^{\circ} 59^{\prime} 37.73^{\prime \prime}\right)$, District - Kargil, in Ladakh region of Jammu and Kashmir at an altitude 2,676 $\mathrm{m}(8,780 \mathrm{ft})$ and stored in paper envelopes over a period of more than one year. These stored corms used as explants were treated in $5 \%(\mathrm{v} / \mathrm{v})$ liquid detergent solution (Tween-20) for 10-12 minutes at room temperature. After thorough rinsing in distilled water, they were washed in $70 \%(\mathrm{v} / \mathrm{v})$ ethanol for a brief period (30 seconds) and finally surface-sterilized in $0.15 \%(\mathrm{w} / \mathrm{v}) \mathrm{HgCl}_{2}$ solution for 10 minutes. The explants were then rinsed in sterile distilled water three to four times. Young whole corms and corm buds, dissected out from corms, were cultured on Murashige and Skoog's basal medium (Murashige and Skoog, 1962). Soluble chitosan (Sigma, chitosan content $99.9 \%$ ) was added to the medium prior to autoclaving and the $\mathrm{pH}$ was adjusted to 5.75.8. Tested concentrations of soluble chitosan were $0,0.005,0.015,0.05,0.15,0.5,0.75$ and 1 $\mathrm{g} / 1$. Surface sterilized corms of Colchicum luteum Baker were placed on MS medium ( 5 corms in each of three replicates per treatment). In vitro culture conditions were maintained at $22 \pm 2{ }^{\circ} \mathrm{C}$, $16 \mathrm{~h}$ photoperiod (fluorescent light tubes) in 250 $\mathrm{mL}$ capacity Erlenmeyer flaks containing $50 \mathrm{ml}$ of culture medium for 21 days [Fig. 1 c)]. In vitro parameters including germination percentage, shoot length, leaf number, fresh and dry weights per germinated corm were recorded. Analysis of variance (one-way ANOVA) was carried out, using the least significant difference (LSD) test at $P<0.05$ to compare means.

\section{Results and Discussion:}

At the concentrations of 0.75 and $1 \mathrm{~g} / 1$ of chitosan, the culture medium failed to solidify and these concentrations were removed from the experiment. The effects of different concentrations of soluble chitosan applied in the culture medium on germination and growth of Colchicum luteum Baker is shown in Table 1.

In vitro germination of dormant corms was found to be increased in all concentrations of chitosan used. Use of chitosan at the concentration of $0.5 \mathrm{~g} / 1$ significantly increases percent germination of Colchicum luteum Baker corms on basal medium (Table 1) [Fig. $1 \mathrm{~d}$ )].

Application of 0.015 and $0.5 \mathrm{~g} / 1$ of soluble chitosan led to a significant increase in fresh and dry weight of in vitro grown plantlets. It seems that soluble chitosan promotes proper germination and growth of dormant corms at higher concentrations (Table 1).

The leaf number of in vitro plantlets was not affected by chitosan, but the plantlet length was significantly decreased at $0.5 \mathrm{~g} / 1$ of soluble chitosan, showing a decrease of inter-nodal distances depicting normal growth and development of corms. Application of $0.5 \mathrm{~g} / 1$ chitosan in vitro resulted in improved germination and growth of dormant Colchicum luteum Baker corms, compared to the control. The lower concentrations tested had no significant effect on germination parameters (Table 1).

Study carried out in the present investigation is unique of its kind. Little information is available regarding tissue culture study in this genus. A viable protocol for in vitro multiplication of Colchicum luteum Baker has been proposed by Sing et al. (2012) using corms as explants cultured on MS medium supplemented with 5.0 $\mathrm{mg} / 1 \mathrm{BAP}, 50.0 \mathrm{mg} / 1$ adenine sulphate and 10.0 $\mathrm{mg} / 1$ citric acid for shoot induction and 0.5 $\mathrm{mg} / 1$ IBA for root induction. However, in the present investigation in vitro germination is achieved without hormones on MS basal medium supplemented with soluble chitosan. Thus, chitosan must have exhibited its growth stimulatory activity by signaling indigenous biosynthesis of one or more growth regulators as reported earlier by Day et al. (2001) in soybean cell culture, Uddin et al. (2004) in Eustoma cell culture and Shao et al. (2005) in germinating Maize seeds.

Table 1: Effect of different concentrations of soluble chitosan applied in the culture medium on germination and growth of Colchicum luteum Baker corms.

\begin{tabular}{|l|l|l|l|l|l|l|l|}
\hline \multirow{2}{*}{$\begin{array}{l}\text { In Vitro growth } \\
\text { characters studied }\end{array}$} & \multicolumn{6}{|l|}{ Chitosan concentration (g/1) } & LSD \\
\cline { 2 - 8 } & 0 & 0.005 & 0.015 & 0.05 & 0.15 & 0.5 & $\mathbf{( 5 \% )}$ \\
\hline Germination percentage & 48.88 & 56.66 & 55.75 & 56.66 & 55.56 & $66.66^{*}$ & 0.542 \\
\hline Fresh weight (g/ corm) & 0.3022 & 0.326 & 0.3378 & 0.299 & 0.3168 & $0.429 .2^{*}$ & 69.32 \\
\hline Dry weight (g/corm) & 0.0298 & 0.0368 & $0.0392^{*}$ & 0.034 & 0.036 & $0.0492^{*}$ & 7.64 \\
\hline Shoot length (cm) & 6.85 & 7.0 & 6.55 & 6.05 & 6.75 & $5.05^{*}$ & 2.43 \\
\hline Leaf number per corm & 4.4 & 4.5 & 4.4 & 4.3 & 4.5 & 4.9 & 1.8 \\
\hline
\end{tabular}

LSD - the values of least significant difference test at $\mathrm{P}<0.05$;

*Significant difference (positive or negative) from control at $\mathrm{P}<0.05$. 

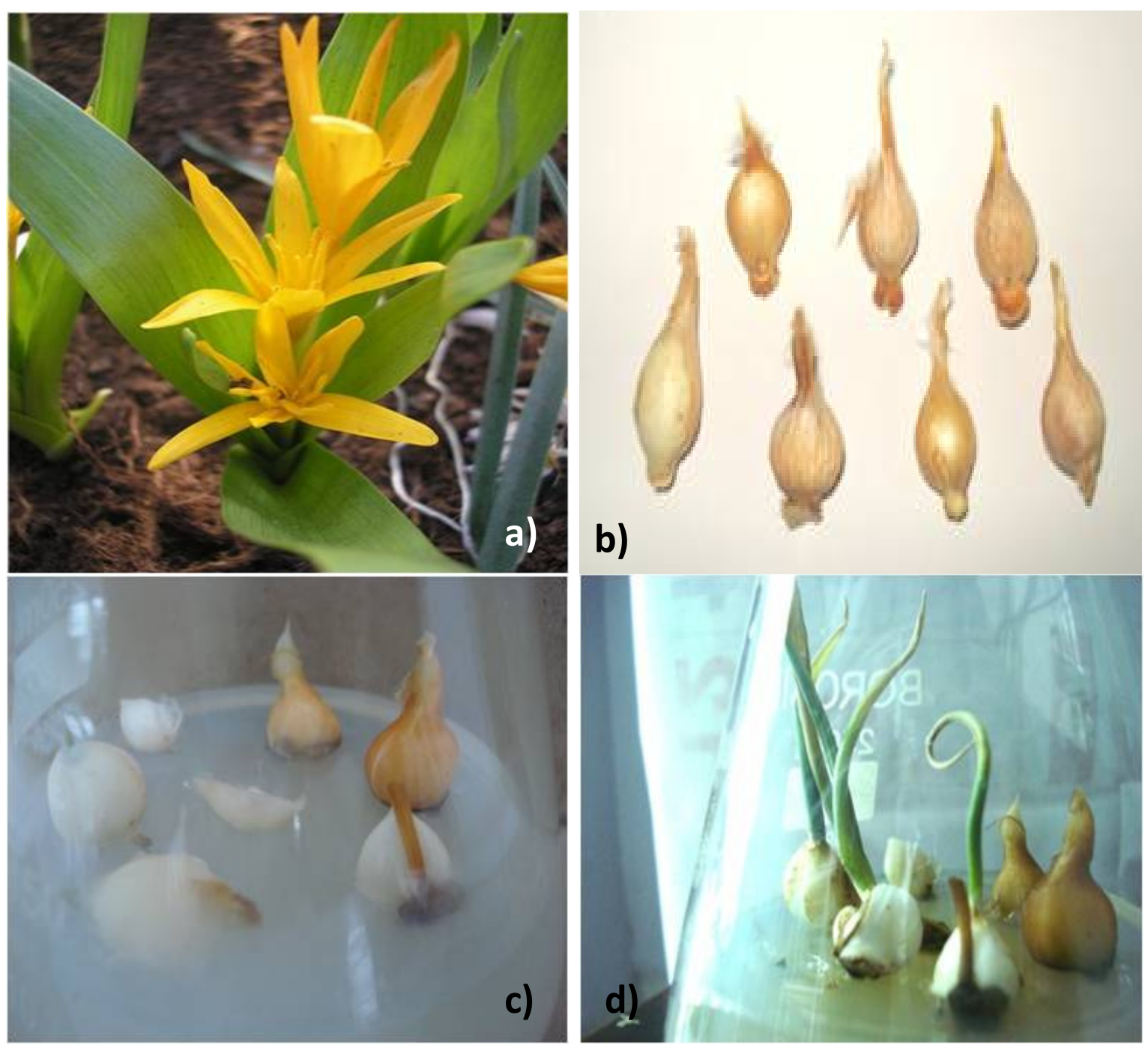

Figure. 1 a) Colchicum luteum Baker plant in its natural habitat.

b) Stored dormant corms of Colchicum luteum Baker.

c) Colchicum luteum corms inoculated on MS nutrient medium supplemented with chitosan.

d) Germinated corms of Colchicum luteum Baker on MS medium supplemented with $0.5 \mathrm{~g} / 1$ chitosan.

\section{Conclusion:}

The present results showed that chitosan, a plant growth promoter and defense booster could alleviate stress caused by storage conditions in dormant Colchicum luteum Baker corms by stimulating growth regulators. Application of chitosan in vitro at $0.5 \mathrm{~g} / 1$ concentration mainly influenced germination and growth. Soluble chitosan can be added without extra manipulation to the culture medium before autoclaving. Moreover, chitosan is used in small amounts in MS medium without hormones so the cost of in vitro culturing is minimized.

The present study indicates that soluble chitosan can be successfully incorporated into culture medium for improving germination and growth of Colchicum luteum Baker corms in in vitro exploration studies.

\section{Acknowledgements:}

The authors acknowledge their gratitude to Prof. A. D. Choudhary, Dept. of Botany, RTM Nagpur University for guidance and availing tissue culture facility.

\section{References:}

Ait Barka, E., Eullaffroy, P., Clément, C. and Vernet, G. (2004): Chitosan improves development, and protects Vitis vinifera L. against Botrytis cinerea. Plant Cell Reports. Vol. 22: Pp. 608-614.

Boonlertnirun, S., Boonraung, C. and Suvanasara, R. (2008): Application of Chitosan in rice production. Journal of Metals, Materials and Minerals. Vol. 18 (2): Pp. 47-52. 
Chandrkrachang, S., Sompongchaikul, P. and Teuntai, S. (2003): Effect of chitosan applying in multicuture crop plantation. National ChitinChitosan Conference July 17-18, 2003, Chulalongkorn University, Bangkok, Thailand pp: 158-160.

Cheah, L. H., Page, B. B. C. and Shepahrd, R. (1997): Chitosan coating for inhibition of Sclerotina in carrots. New Zealand Journal of Crop and Horticultural Science. Vol. 25: Pp. 8992.

Chopra, R. N. (1969): Supplement to glossary of Indian medicinal plants. CSIR New Delhi.

Day, R. B., Okada, M., Ito, Y., Tsukada, K., Zaghouani, H., Shibuya, N. and Stacey, G. (2001): Binding sites for chitin oligosaccharides in soybean plasma membrane. Plant Physiology. Vol. 126: Pp. 1162-1173.

Eigsti, O. J. and Dustin, P. (1957): Colchicine - in Agriculture, Medicine, Biology and Chemistry. The Iowa State College Press, Ames, IA, USA.

Kapadia, V. H., Dev, S., Rao, R. S. and Ansari, M. Y. (1972): New source of colchicine in Iphigenia. Phytochemistry. Vol. 11: Pp. 1193.

Murashige, T. and Skoog, F. (1962): A revised medium for rapid growth and bio-assays with tobacco tissue cultures. Physiol. Plant. Vol.15: Pp. 473-497.

Ohta, K., Taniguchi, A., Konishi, N. and Hosoki, T. (1999): Chitosan treatment affects plant growth and flower quality in Eustoma grandiflorum. Horticultural Science. Vol. 34: Pp. 233-237.

Reddy, M. V. B., Arul, J., Angers, P. and Coutur, L. (1999): Chitosan treatment of wheat seeds induces resistance to Fusarium graminearium and improved seed quality. Journal of Agriculture and Food Chemistry. Vol. 47: Pp. 1028-1216.

Ruan, S. L. and Xue, Q. Z. (2002): Effects of chitosan coating on seed germination and salt- tolerance of seedlings in hybrid rice (Oryza sativa L.). Acta Agronomica Sinica. Vol. 28 (6): Pp. 803-808.

Saoji, D. D. (2008): Investigations on growth and immunostimulant activities of alginate and chitosan. Ph. D. Thesis. Department of Botany, RTM, Nagpur University, Nagpur.

Shao, C. X, Hu, J., Song, W. J. and Hu, W. M. (2005): Effects of seed priming with chitosan solutions of different acidity on seed germination and physiological characteristics of maize seedlings. Journal of Zhejiang UniversityAgriculture and Life Science. Vol. 31(6): Pp. 705708.

Singh, S., Banerjee, M. and Haider, Z. A. (2013): Conservation of Colchicum luteum Baker through Micro Propagation. Journal of Research (BAU). Vol. 25 (1): Pp. 96-100.

Uddin, A. F. M. J., Hashimoto, F., Shimiza, K. and Sakata, Y. (2004): Monosaccharides and chitosan sensing in bud growth and petal pigmentation in Eustoma grandiflorum (Raf.) Shinn. Scientia Horticulturae. Vol. 100: Pp.127138.

Wagh, P. J. (2012): Investigations on biological activity of radiation degraded products of alginate and chitosan with particular reference to growth and defense response. Ph. D. Thesis. Department of Botany, RTM Nagpur University, Nagpur.

Wealth of India (1959): C S I R, New Delhi, India

Yamaguchi, T., Yuki, I. and Shibuya, N. (2000): Oligosaccharide elicitors and their receptors for plant defense responses. Trends in Glycoscience and Glycotechnology. Vol. 12: Pp. 113-120.

Zhou, Y. G., Yang, Y. D., Qi, Y. G., Zhang, Z. M., Wang, X. J. and Hu, X. J. (2002): Effects of chitosan on some physiological activity in germinating seed of peanut. Journal of Peanut Science. Vol. 31 (1): Pp. 22-25. 